\title{
Performance Evaluation of Stone Mastic Asphalt and Hot Mix Asphalt Mixtures Containing Recycled Concrete Aggregate
}

\author{
Mohammad Saeed Pourtahmasb and Mohamed Rehan Karim \\ Department of Civil Engineering, Center for Transportation Research (CTR), Faculty of Engineering, University of Malaya (UM), \\ 50603 Kuala Lumpur, Malaysia
}

Correspondence should be addressed to Mohammad Saeed Pourtahmasb; sp.um.eng@gmail.com

Received 1 June 2014; Revised 12 August 2014; Accepted 27 August 2014; Published 7 September 2014

Academic Editor: Sridhar Komarneni

Copyright ( 2014 M. S. Pourtahmasb and M. R. Karim. This is an open access article distributed under the Creative Commons Attribution License, which permits unrestricted use, distribution, and reproduction in any medium, provided the original work is properly cited.

\begin{abstract}
Environmental and economic considerations have encouraged civil engineers to find ways to reuse recycled materials in new constructions. The current paper presents an experimental research on the possibility of utilizing recycled concrete aggregates (RCA) in stone mastic asphalt (SMA) and hot mix asphalt (HMA) mixtures. Three categories of RCA in various percentages were mixed with virgin granite aggregates to produce SMA and HMA specimens. The obtained results indicated that, regardless of the RCA particular sizes, the use of RCA to replace virgin aggregates increased the needed binder content in the asphalt mixtures. Moreover, it was found that even though the volumetric and mechanical properties of the asphalt mixtures are highly affected by the sizes and percentages of the RCA but, based on the demands of the project and traffic volume, utilizing specific amounts of RCA in both types of mixtures could easily satisfy the standard requirements.
\end{abstract}

\section{Introduction}

In recent years, many studies have been carried out on the use of construction and demolition (C\&D) wastes in developed countries. The most considerable interest is the reuse of waste materials in new construction sectors. It is the intention of scientists and researchers, as well as people in authority, to explore waste material recycling for environmental and economic advantages and also the possibility of solid waste reuse in road construction [1]. Reusing waste material is one of the many ways to solve the problem of excess solid waste materials in industrial and urban areas. It can make significant contributions to the environment and the economy, such as (1) reducing the overuse of natural resources and saving them from exhaustion, (2) reducing the environmental pollution levels from waste materials generated in urban and industrial areas, and (3) contributing to savings in energy and money. Therefore, in order to reduce their negative impacts on the environment, it is logical to reuse these waste materials in engineering and industrial applications [2].

Recycled concrete aggregate (RCA) is produced by crushing demolished concrete structures such as buildings, bridges, and dams. RCAs were initially used as filler materials and based on previous researches; it could be used as road subbase materials and in nonstructural concrete applications such as curbs, canal lining, driveways, and footpaths [3-6]. Waste materials to be used in pavement constructions can come from different sources, including demolition of civil engineering structures and industrial wastes. These materials are mostly classified based on their resources like industrial by-products (steel slag and coal fly ash), demolition byproducts (concrete, tiles, and bricks), and road by-products such as RAP (recycled asphalt pavements) or RCP (recycled concrete pavements) [7]. Concrete is the most basic construction material all around the world, which essentially consists of aggregates (sand, crushed stone, or gravel), cement, and water. Environmental and economic considerations have encouraged governments to find ways to use recycled materials in new productions. When the concrete structure is demolished, repaired, or renewed, recycling is an increasingly common method of reusing the rubble concretes. On the other hand, in recent years, the knowledge of continued wholesale extraction and use of aggregates from natural resources have been questioned at the international level. 
This is the result of the depletion of quality primary aggregates and greater awareness on environmental protection. Moreover, the availability of natural resources for future generations has also been considered as an important issue [8].

\section{Use of RCA in Asphalt Mixtures}

Waste material from demolished concrete structures is one of the largest wastes in the entire world. For example, this amount of waste in Europe is around 180 million tons per year or $480 \mathrm{~kg}$ per capita per year [9]. These ranges are from over $700 \mathrm{~kg}$ per person in a year in Germany and the Netherlands and 500 in UK to almost 200 in Greece, Sweden, and Ireland. Therefore, concrete waste has become a global concern that requires a sustainable solution [10]. Recent studies on RCAs have shown the acceptable potential to produce strong and durable materials for HMA pavements. However, the amount of fine RCA should not exceed more than 30 percent of the fine aggregate portion of the pavement mixtures. This is because as the fine RCA increases, the density will be decreased due to higher mortar in fines which causes higher water absorption in the mixture [11]. In 2003, the Federal Highway Administration (FHWA) proved the acceptable performance of RCA in base and subbase materials of roads which not only significantly reduce the costs but also have many environmental benefits [12]. In latter investigation, in 2004, California Department of Transportation (Cal-trans) discovered that even though the RCA collection startups costs are high, in general, overhead costs are significantly reduced [13]. Recycled concrete aggregates are different from virgin aggregates due to the amount of cement pastes remaining on the surface of the recycled aggregates after undergoing the recycling process $[14,15]$. The presence of cement paste increases the porosity of the aggregates, reduces the particle density, and thus affects the quality and water absorption capacity of the RCA. Therefore, utilizing RCA in hot mix asphalt (HMA) mixtures affected the volumetric properties and performance of HMA mixtures [16].

In a joint experiment, Paranavithana and Mohajerani [15] performed experiments on the effects of recycled concrete aggregates on the properties of HMA, in which 50\% RCA by dry weight of total aggregates was used as coarse aggregate in the asphalt mixtures. The performance tests carried out on these mixes showed that using RCA in HMA mixtures lowered the resilient modulus and creep resistance of the mix and increased the stripping potential of them. In addition, the mixes containing RCA showed large variations in strength under dry and wet conditions. In 2007, Wong et al. [11] studied on the utilization of RCA as a partial aggregate substitution in HMA. Three HMA mixes were included in the study by substituting granite filler/fines with $6 \%$ untreated, $45 \%$ untreated, and $45 \%$ heat-treated recycled concrete, respectively. All three mixes passed the wearing course criteria specified by the Singapore Land Transport Authority (SLTA), based on the Marshall mix design method. The performance tests on the mix with 6\% RCA showed comparable resilient modulus and creep resistance to those of the traditional HMA mix. The mixes with the higher percentage of RCA showed higher resilient modulus and resistance to creep.

Another research was conducted by Topal et al. [16] who studied the use of recycled concrete aggregates in hot mix asphalt. They found that RCA can substitute HMA aggregates and achieve the required Marshall stability (MS) and indirect tensile strength (IDT) of the mixtures. The test results indicated that the Marshall stability values increased with the increase of RCA in the mix. However, the voids in mineral aggregate (VMA) and the voids filled with asphalt (VFA) decreased with the increase in RCA content. This was believed to be due to crushing of RCA by the Marshall compactor during compaction. The tensile strength of the mix containing RCA was found to be higher than that of the control mix as the internal friction of RCA was higher than that of natural limestone aggregates. Eventually, RCA was not recommended to be used in the wearing course due to RCA's susceptibility to abrasion by vehicles.

Mills-Beale and You [17] investigated the feasibility of using RCA for a low-volume traffic road in Michigan, with $25 \%, 35 \%, 50 \%$, and $75 \%$ of virgin aggregates by the weight of total aggregates substituted with RCA. It was found that increasing the RCA's content decreased the VMA and VFA of the mixes. The laboratory test results indicated that all the 4 mixes containing RCA passed the minimum rutting specification of 0.32 inch rut depth. Dynamic modulus test results showed that the stiffness of the mixtures containing RCA was less than control mix, but using RCA in HMA mixtures reduced the energy needed for compaction. In terms of moisture susceptibility, all the mixes (except $75 \%$ RCA mix) passed the tensile strength ratio (TSR) of $80 \%$. Based on the literatures, limited studies have been carried out on the usage of RCA in dense-graded (DG) asphalt mixtures. However, due to the success obtained by using RCA in HMA, it appears that there is a need to evaluate the use of RCA in stone mastic asphalt (SMA) mixtures as well. In this paper, the possibility of using RCA in SMA and HMA mixtures has been investigated and the test results were tabulated and discussed.

\section{Materials and Methods}

3.1. Materials. Granite aggregates, $80 / 100$ penetration grade bitumen, hydrated limestone powder, oil palm fiber, and recycled concrete aggregates (RCA) were obtained for use in this research. The crushed granite aggregates were provided from Kajang rock quarry (located near Kuala Lumpur, capital of Malaysia). To provide the RCA, concrete infrastructures were first demolished and crushed into large chunks. The steel bars were subsequently removed and the concrete debris was transferred to a crusher machine to produce proper sized aggregates. Bitumen, filler, and fibers (to be used in SMA) were obtained from the university materials supplier. Figures 1 and 2 present the used aggregate gradation in this research for SMA and HMA mixtures based on the asphalt institute (AI) and ASTM D3515. Moreover, physical properties of RCA, granite aggregates, and 80-100 binder are, respectively, outlined in Tables 1, 2, and 3. 
TABLE 1: Physical properties of RCA.

\begin{tabular}{lccc}
\hline Test & Method & Value & Standard requirement \\
\hline LA abrasion & ASTM C131 & 24.5 & Below 30\% \\
Aggregate impact value & BS812: Part 3 & 11.31 & Below 15\% \\
Aggregate crushing value & BS812: Part 3 & 28.3 & Below 30\% \\
Flakiness index & BS812: Part 3 & 9.8 & Below 20\% \\
Angularity number & BS812: Part 3 & 8.40 & Between 6 to 9 \\
Elongation index & BS812: Part 3 & 5.35 & Below 20\% \\
Sand equivalent & AASHTO T176 & 65 & Above 45\% \\
Water absorption (coarse) & ASTM C 127-07 & - \\
Water absorption (fines) & ASTM C 128-07 & 2.69 & - \\
Specific gravity (coarse) & ASTM C 127-07 & 4.28 & - \\
Specific gravity (fine) & ASTM C 128-07 & 2.18 & - \\
\hline
\end{tabular}

TABLE 2: Physical properties of granite.

\begin{tabular}{lccr}
\hline Test & Method & Value & Standard requirement \\
\hline LA abrasion & ASTM C131 & 18.3 & Below 30\% \\
Aggregate impact value & BS812: Part 3 & 6.21 & Below 15\% \\
Aggregate crushing value & BS812: Part 3 & 20.82 & Below 30\% \\
Flakiness index & BS812: Part 3 & 7.9 & Below 20\% \\
Angularity number & BS812: Part 3 & 6.31 & Between 6 to 9 \\
Elongation index & BS812: Part 3 & 8.10 & Below 20\% \\
Polished stone value & BS812: Part 3 & 50.75 & Above 40 \\
Soundness & BS812: Part 3 & 5.25 & Below 12\% \\
Water absorption (coarse) & ASTM C 127-07 & - \\
Water absorption (fines) & ASTM C 128-07 & 1.11 & - \\
Specific gravity (coarse) & ASTM C 127-07 & 2.61 & - \\
Specific gravity (fine) & ASTM C 128-07 & 2.64 & - \\
\hline
\end{tabular}

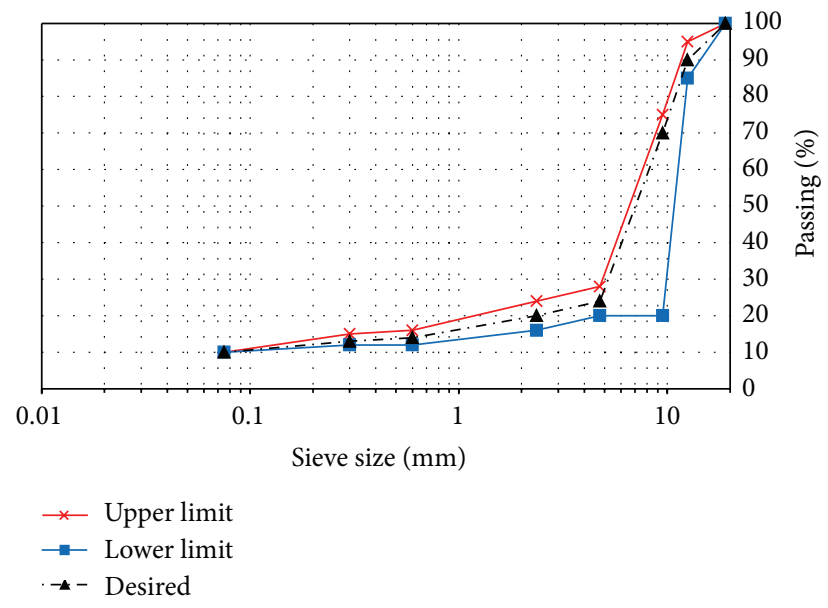

FIGURE 1: SMA aggregate gradation based on the Asphalt Institute (2007).

\subsection{Methods}

3.2.1. Sample Preparation. In this study, SMA and HMA mixtures were compacted by using roller compactor and the required specimens were cored out of the compacted slabs to evaluate the performance tests. $20 \%, 40 \%, 60 \%$, and $80 \%$

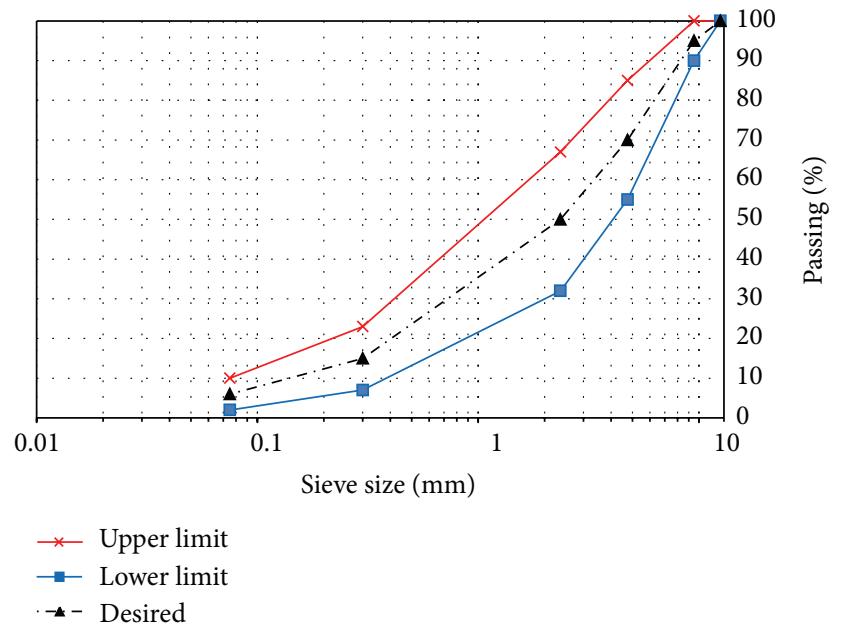

FIGURE 2: HMA aggregate gradation based on ASTM D3515.

RCA were blended with virgin aggregates to produce the asphalt specimens. However, these percentages were divided into three categories comprising of coarse RCA (C-RCA), fine RCA (F-RCA), and a mix of both (M-RCA) with the virgin aggregates (VA) based on the mentioned values. Also, the $0 \%$ 
TABLE 3: Physical properties of $80 / 100$ binder.

\begin{tabular}{lccr}
\hline Test & Method & Value & Standard requirement \\
\hline Penetration & ASTM D5 & 84.7 & $84-95$ \\
Softening point & ASTM D36 & 47.2 & $47-49$ \\
Flash point & ASTM D92 & 289 & $275-302$ \\
Fire point & ASTM D92 & 303 & $>302$ \\
Viscosity at $135^{\circ} \mathrm{C}$ & ASTM D4402 & 0.254 & - \\
Viscosity at $165^{\circ} \mathrm{C}$ & ASTM D4402 & 0.099 & - \\
Specific gravity & ASTM D70 & 1.03 & - \\
\hline
\end{tabular}

TABLE 4: SMA/HMA aggregate content.

\begin{tabular}{lccc}
\hline VA (\%) & C-RCA & F-RCA & M-RCA \\
\hline \multirow{2}{*}{80} & 20 & - & - \\
& - & 20 & - \\
& - & - & 20 \\
\hline \multirow{2}{*}{60} & 40 & - & - \\
& - & 40 & - \\
& - & - & 40 \\
40 & 60 & - & - \\
& - & 60 & - \\
& - & - & 60 \\
\hline \multirow{2}{*}{20} & 80 & - & - \\
& - & 80 & - \\
& - & - & 80 \\
\hline
\end{tabular}

TABLE 5: Optimum asphalt content (OAC) of SMA and HMA mixtures.

\begin{tabular}{lcc}
\hline Mix design & OAC of SMA (\%) & OAC of HMA (\%) \\
\hline 100\% VA & 6.2 & 5.1 \\
$20 \%$ F-RCA & 6.2 & 5.5 \\
$40 \%$ F-RCA & 6.3 & 5.9 \\
$60 \%$ F-RCA & 6.5 & 6.5 \\
$80 \%$ F-RCA & 6.5 & 7.3 \\
20\% C-RCA & 6.4 & 5.4 \\
$40 \%$ C-RCA & 7.0 & 5.5 \\
$60 \%$ C-RCA & 7.9 & 6.2 \\
$80 \%$ C-RCA & 8.9 & 6.8 \\
20\% M-RCA & 6.4 & 5.4 \\
$40 \%$ M-RCA & 6.6 & 5.9 \\
$60 \%$ M-RCA & 7.0 & 6.4 \\
$80 \%$ M-RCA & 7.8 & 7.0 \\
\hline
\end{tabular}

RCA mixture (100\% VA mix) was performed as the control mix. SMA and HMA aggregates content are shown in Table 4.

Marshall mix design method was used to measure the optimum asphalt content (OAC) of SMA and HMA mixtures and results are displayed in Table 5. To make a better adhesion between aggregates and bitumen during the mix procedure and remove the excessive dusts from the surface of the RCAs, the crushed concretes were submerged, washed, and then dried well before being used in the asphalt mixtures. The required amounts of aggregates, fillers, and RCA were weighed and placed into the oven at $200^{\circ} \mathrm{C}$ for 2 hours. The required quantity of $80 / 100$ binder was weighed and heated for a period of 1 hour at $150^{\circ} \mathrm{C}$.

Hot aggregates (including RCA) were mixed with binder at $160 \pm 5^{\circ} \mathrm{C}$ until all the aggregates were coated. However, to prevent binder drain down (in SMA mixtures), the loose form fibers ( 0.3 percent by the weight of total mix) were blended with the hot aggregates before the binder being introduced. Finally, the weighed amount of filler was added and mixed well. All the mixtures were conditioned for 4 hours at $150^{\circ} \mathrm{C}$ and then compacted with the target of $4 \%$ air voids content.

\subsection{Marshall Tests}

3.3.1. Density and Air Voids Tests. Bulk density was determined in accordance with ASTM D2726. Bulk density was measured by weighing in air and water using the following equations:

$$
\begin{gathered}
d=G_{m b} \times \rho_{w}, \\
G_{m b}=\left[\frac{W_{D}}{\left(W_{\mathrm{SSD}}-W_{\mathrm{SUB}}\right)}\right] .
\end{gathered}
$$

Air voids analysis was carried out in accordance with ASTM D 3203. The air voids value of the specimens was measured using the following equation with the value of calculated theoretical maximum density (TMD):

$$
\mathrm{VTM}=\left[1-\left(\frac{d}{\mathrm{TMD}}\right)\right] \times 100,
$$

where $d$ = bulk density $\left(\mathrm{g} / \mathrm{cm}^{3}\right), G_{m b}$ is the bulk specific gravity of the mix, $G_{s b}$ is the bulk specific gravity of the aggregates, $\rho_{w}$ is the density of water $\left(\mathrm{g} / \mathrm{cm}^{3}\right), W_{D}$ is the mass of specimen in air $(\mathrm{g}), W_{\text {SUB }}$ is the mass of specimen in water $(\mathrm{g}), W_{\text {SSD }}$ is the saturated surface dry mass (g), and VTM is the voids in total mix.

3.3.2. Marshall Stability and Flow Tests. Marshal stability and flow tests were accomplished in accordance with ASTM D1559. The maximum load carried by a compacted SMA and HMA specimens at $140^{\circ} \mathrm{F}\left(60^{\circ} \mathrm{C}\right)$, with a loading rate of two inches per minute $(50.8 \mathrm{~mm} / \mathrm{min})$, was defined as Marshall stability. Also, the vertical deformation of the asphalt specimen at the same time of running the Marshall stability (measured from start of loading, until the stability begins to decrease) was defined as flow. 
3.3.3. Voids in Mineral Aggregates (VMA) and Voids Filled with Asphalt (VFA) Tests. Voids in mineral aggregates (VMA) and voids filled with asphalt (VFA) were determined by using the given equations:

$$
\begin{gathered}
\mathrm{VMA}=100 \times\left\{1-\left[\frac{G_{m b}\left(1-P_{b}\right)}{G_{s b}}\right]\right\}, \\
\mathrm{VFA}=\left[\frac{(\mathrm{VMA}-\mathrm{VTM})}{\mathrm{VMA}}\right] \times 100,
\end{gathered}
$$

where $P_{b}$ is the asphalt content, percent by the weight of the mix, VMA is the voids in mineral aggregates, VFA is the voids filled with asphalt, and $T_{R}$ is the tracking rate.

3.4. Resilient Modulus $\left(M_{R}\right)$. The modulus of asphalt is an essential parameter for designing flexible pavements during the application of the elastic-layered system theory. Over the years, resilient modulus $\left(M_{R}\right)$ test has been one of the most popular tests for asphalt mixtures and is being used to measure the response of the asphaltic pavements to the actual wheel loads [18]. In this study, the material testing apparatus (MATTA) was used to determine the resilient modulus of the SMA and HMA specimens. This test was carried out in accordance with ASTM D4123 to apply indirect repeated axial pulses to the asphalt specimens at $25^{\circ} \mathrm{C}$ and measuring the horizontal deformations of the curved surface of the specimens with two attached linear variable displacement transducers (LVDTs). Each specimen was kept for at least two hours at $25^{\circ} \mathrm{C}$ (for conditioning) before starting the test and results were automatically recorded by using computer software based on the given equation:

$$
M_{R}=\frac{P}{H t}(0.27+\mu),
$$

where $M_{R}$ is the resilient modulus (Psi), $P$ is the applied load (pounds), $H$ is the total recoverable horizontal deformation (inches), $t$ is the sample thickness (inches), and $\mu$ is the Poisson's ratio.

3.5. Loaded Wheel Tracking (LWT). Rutting resistance is one of the most important and critical performance requirements of asphalt mixtures and this role becomes more critical in hot climates. There are several tests used to evaluate rutting of asphalt mixtures such as Marshall test, wheel track test, static and dynamic creep tests, and indirect tensile tests [19]. Hence, due to the better field simulation, the wheel tracking test is the most commonly recommended test [20]. Loaded wheel tracking (LWT) test was conducted in accordance with British Standard (BS 598-110) to determine the wheel tracking rate and depth at $45^{\circ} \mathrm{C}$ for the moderate to heavily stressed sites. Table 6 presents the maximum allowable rut depth and rut rate values of asphalt mixtures at 45 and $60^{\circ} \mathrm{C}$.

In the present study, $78 \mathrm{SMA}$ and $78 \mathrm{HMA}$ core specimens (72 specimens containing RCA and 6 specimens as a control mix, made of virgin aggregates) with $200 \mathrm{~mm}$ diameter were cored out from fabricated slabs. Each core specimen was preconditioned at $45^{\circ} \mathrm{C}$ for 6 hours before starting the actual test. The loading wheel was set in motion to reciprocate over the specimen at the rate of 21 cycles per minute. The $520 \pm 5 \mathrm{~N}$ load was applied to the surface of the specimen through a $50 \mathrm{~mm}$ width moving wheel, and the rut depth value was recorded every 5 minutes (105 cycles). The test was continued for 45 minutes or until $15 \mathrm{~mm}$ deformation occurred in the specimen (whichever comes first). Tracking rate $\left(T_{R}\right)$ and wheel tracking rate $\left(W_{\mathrm{TR}}\right)$ were defined using the given equations:

$$
\begin{gathered}
T_{R}=3.6\left(r_{(n)}-r_{(n-3)}\right)+\left(r_{(n-1)}-r_{(n-2)}\right), \\
W_{\mathrm{TR}}=10.4 \times T_{R M} \times \frac{\omega}{L},
\end{gathered}
$$

where $r_{n}$ is the depth measurement at $n$th reading, $W_{\mathrm{TR}}$ is the wheel tracking rate, $T_{\mathrm{RM}}$ is the mean value of $T_{R}, \omega$ is the width of wheel's contact area, and $L$ is the total load.

\section{Results and Discussion}

\subsection{Marshall Tests}

4.1.1. Density and Air Voids Tests. Figure 3 displays the results of comparison between the influence of RCA on the density and VTM (voids in total mix) values of SMA and HMA specimens. The measured density values of SMA and HMA mixtures containing $100 \%$ virgin granite aggregates (VA) were 2.314 and $2.438 \mathrm{~kg} / \mathrm{cm}^{3}$. Test results indicated that the density values of SMA and HMA mixtures decreased with increasing RCA content due to the lower specific gravity and density of RCA (compared to granite), except 20 and $40 \%$ FRCA-SMA in which density values slightly increased.

In terms of air voids, the SMA and HMA specimens were produced and compacted with the target of $4 \%$ VTM content. The calculated VTM values indicated that, regardless of the RCA content in the SMA and HMA asphalt mixtures, the air voids could be easily controlled. SMA specimens containing 80\% C-RCA and 80\% M-RCA showed slightly higher VTM values compared to the other asphalt specimens which could be due to the breaking of the C-RCA during compaction.

4.1.2. Marshall Stability and Flow Tests. Regardless of the amount of RCA content in asphalt mixtures, the Marshall stability (MS) values of the HMA specimens were found considerably higher than SMA specimens due to its dense gradation of the aggregates. The calculated Marshall stability (MS) values for SMA and HMA mixtures containing 100\% VA were 10.63 and $14.63 \mathrm{KN}$. Figure 4 displays the MS and flow values of SMA and HMA mixtures containing different percentages of RCA content. Test results indicated that $20 \%$ and $40 \%$ F-RCA could increase the MS values of SMA mixtures up to 10.66 and $10.77 \mathrm{KN}$. Flow values in both types of asphalt mixtures slightly increased with increasing RCA content, but at $80 \%$ C-RCA and M-RCA in the SMA and $80 \%$ F-RCA and M-RCA in the HMA specimens the flow values increased significantly. According to the Asphalt Institute (AI), the minimum stability values of SMA and HMA are expected to be 6.2 and $9 \mathrm{KN}$. The influence of F-RCA in SMA and C-RCA in HMA mixtures was not too much considerable, but as the amount of C-RCA 
TABLE 6: British Standard requirements (BS 598-110).

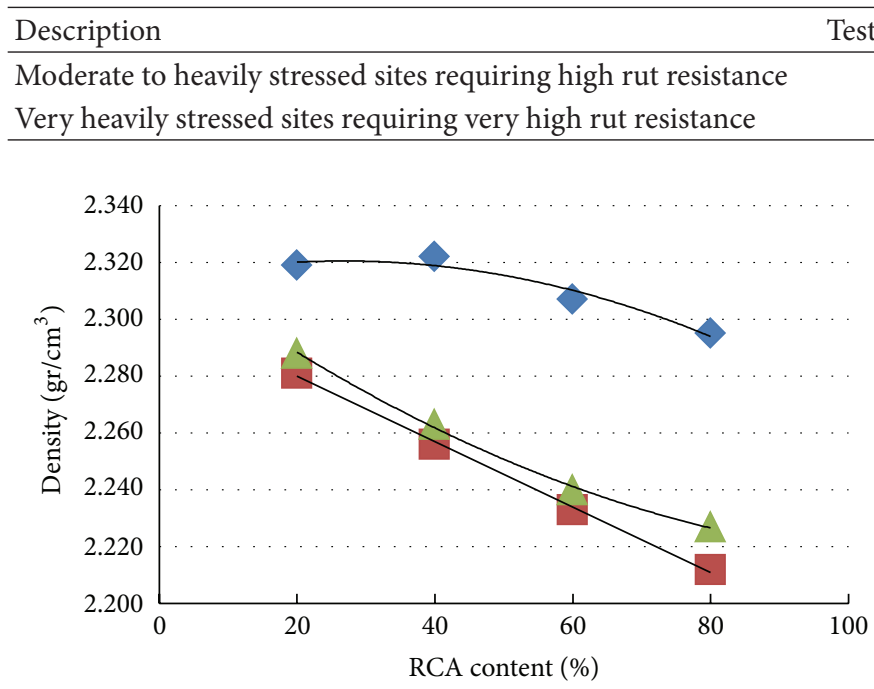

(a)

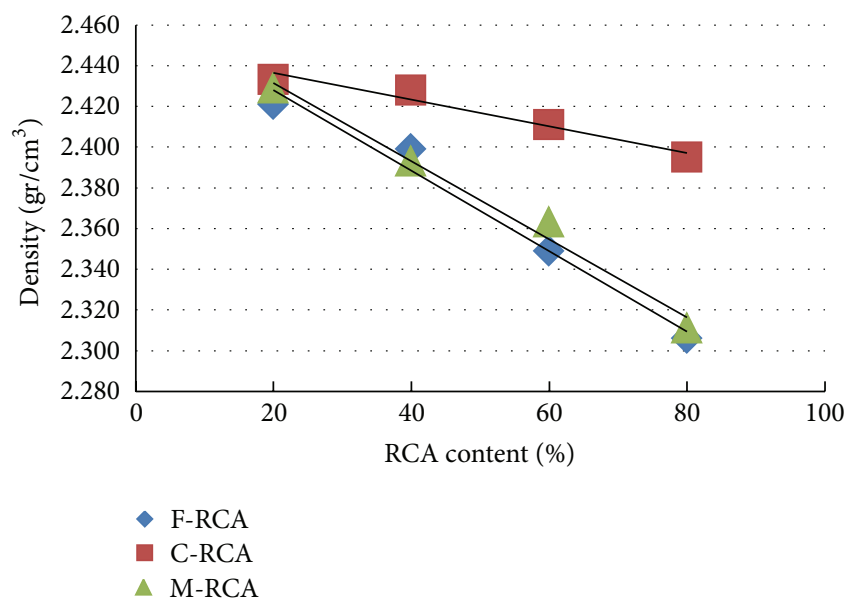

(c)

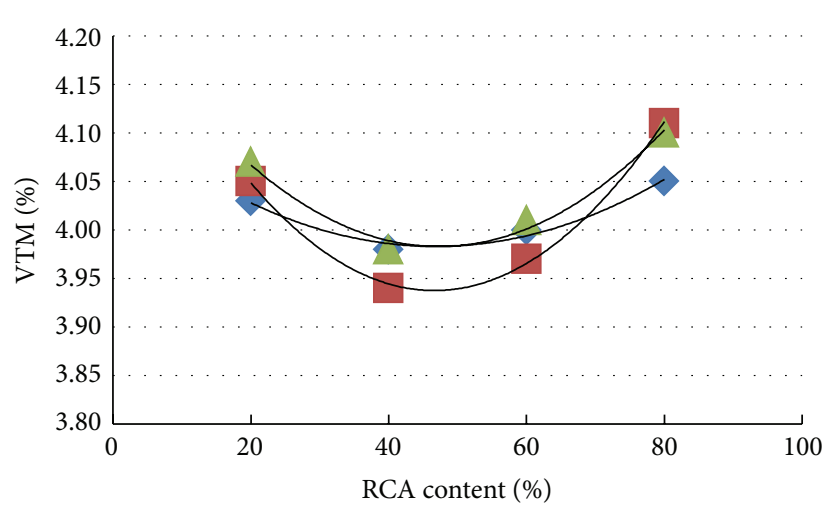

(b)

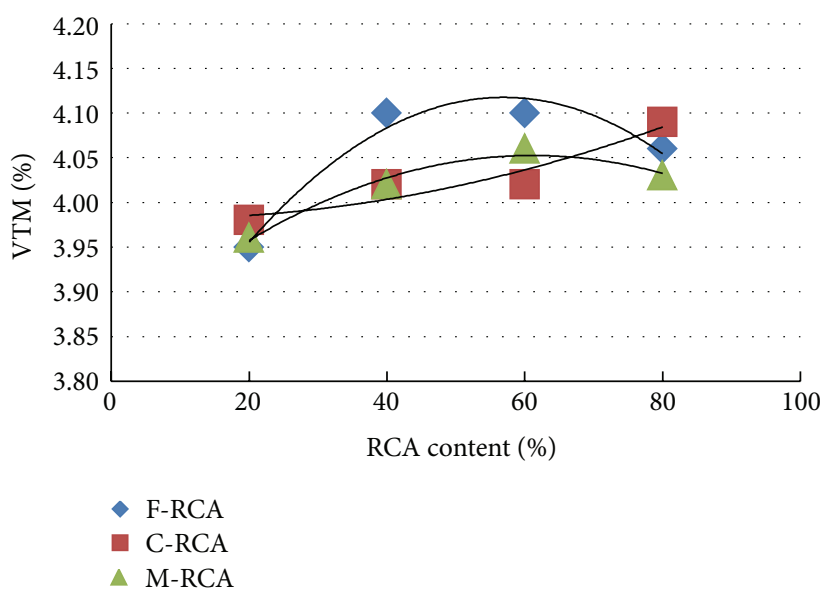

(d)

Figure 3: (a) Density of SMA specimens. (b) Air voids of SMA specimens. (c) Density of HMA specimens. (d) Air voids of HMA specimens.

and M-RCA in SMA mixtures increased to $80 \%$, the stability values decreased to 5.23 and $5.77 \mathrm{KN}$ which are below the AI specification. In HMA mixtures, almost all the specimens performed the acceptable values in terms of stability except for $80 \%$ F-RCA and M-RCA in which the stability decreased to 7.91 and $8.4 \mathrm{KN}$, respectively.

4.1.3. Voids in Mineral Aggregates (VMA) and Voids Filled with Asphalt (VFA) Tests. In the asphalt mixtures containing $100 \%$ VA, the calculated values of voids in mineral aggregates (VMA) and voids filled with asphalt (VFA) were 15.55 and $73.91 \%$ in SMA and 15.44 and $73.64 \%$ in HMA mixtures. Test results indicated that, as the amount of RCA increased in asphalt mixtures, the VMA and VFA values increased as well (Figure 5). It is believed that the higher porosity and absorption of the RCA compared to VA lead to higher OAC levels and caused the mentioned behaviors in the asphalt mixtures. According to the AI, the minimum acceptable value of VMA is dependent on the nominal maximum aggregate size of the mixtures and desired air voids level. The nominal maximum aggregate sizes of HMA and SMA mixtures were 9.5 and $12.5 \mathrm{~mm}$ and the desired air void level was $4 \%$ for both mixtures. Therefore, the allowable VFA values for asphalt specimens are expected to be from $65 \%$ to $78 \%$ for medium traffic volume and from $70 \%$ to $80 \%$ for heavy traffic volume. Also, the minimum VMA values for HMA and SMA are $15 \%$ and $14 \%$. Test results revealed that all the SMA and HMA specimens could meet desired values in terms of VMA and VFA.

4.2. Resilient Modulus $\left(M_{R}\right)$. Figure 6 presents the resilient modulus $\left(M_{R}\right)$ of the SMA and HMA mixtures containing RCA. The $M_{R}$ values of the SMA and HMA mixtures containing RCA were lower than VA mixtures and reduced with any increase in RCA content. SMA specimens containing 20 and $40 \%$ F-RCA showed higher values compared to VA 


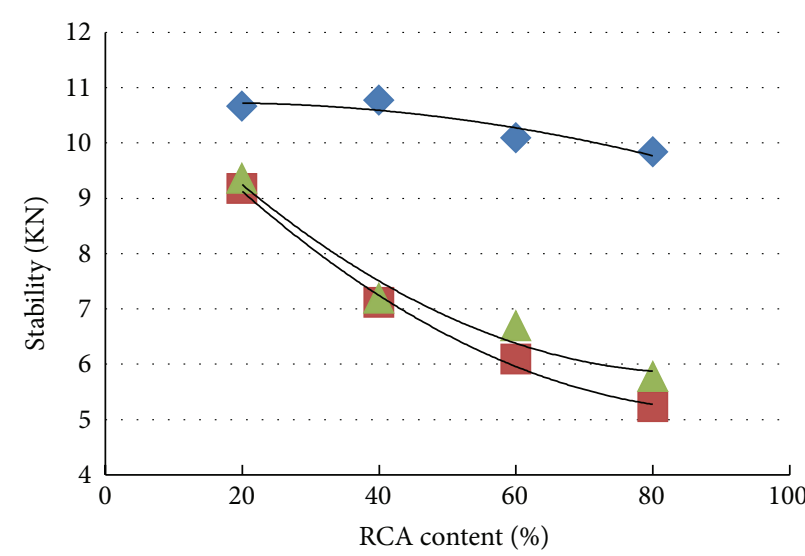

(a)

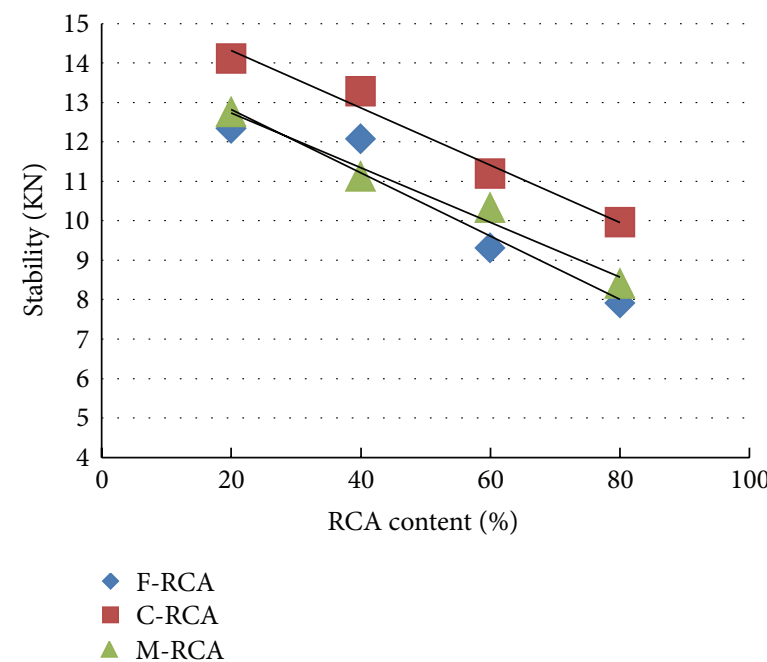

(c)

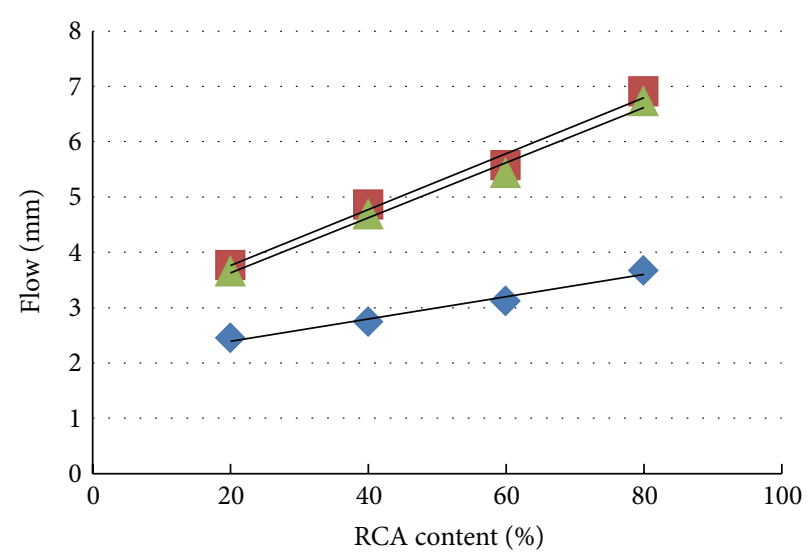

(b)

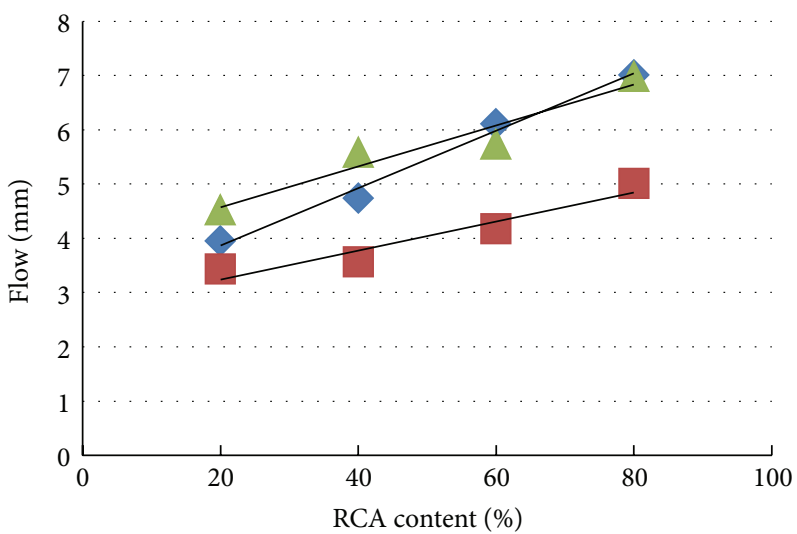

- F-RCA

C-RCA

A M-RCA

FIGURE 4: (a) Stability of SMA specimens. (b) Flow of SMA specimens. (c) Stability of HMA specimens. (d) Flow of HMA specimens.

specimens and the $M_{R}$ values slightly increased up to 2860 and $2906 \mathrm{Mpa}$ while the $M_{R}$ values of VA-SMA and VAHMA were 2814 and $3119 \mathrm{Mpa}$, respectively. According to the standards, the minimum value for resilient modulus of wearing course in conventional flexible pavements is expected to be $2100 \mathrm{Mpa}$. The measured values of resilient modulus in HMA and SMA mixtures indicated that all the specimens could fulfill the minimum requirement except SMA specimens containing $80 \%$ C-RCA and 80\% M-RCA. It is believed that the considerable reduction in $M_{R}$ values by increasing the coarse RCA content in the SMA mixtures are due to the higher amounts of coarse aggregates in SMA in comparison to HMA mixtures.

4.3. Wheel Tracking Depth. Figure 7 illustrates the loaded wheel tracking test results and the effect of C-RCA on SMA and HMA specimens in terms of permanent deformation. The rut depth values for SMA mixtures with 0, 20, 40, 60, and $80 \%$ C-RCA content during 45 minutes were 1.65, 2.52, $3.63,4.46$, and $6.17 \mathrm{~mm}$, respectively. Moreover, the rut depth values for HMA mixtures containing the same amount of
C-RCA content were 2.90, 2.91, 3.00, 4.09, and $6.33 \mathrm{~mm}$. As the C-RCA content increased from $0 \%$ (VA mix) to 20, 40, 60, and $80 \%$, the values of rut depth increased by $52.7,120,170.3$, $273.9 \%$ in SMA and by $0.34,3.45,41.03$, and $118.27 \%$ in HMA specimens. It was found that the influence of C-RCA in SMA specimens was considerably higher than HMA mixtures.

Figure 8 demonstrates the rut depth values of the SMA and HMA specimens containing F-RCA. SMA mixtures with $0,20,40,60$, and 80\% F-RCA showed 1.65, 1.60, 1.41, 2.97, and $3.28 \mathrm{~mm}$ rut depths and HMA specimens showed 2.90, $2.96,3.31,4.47$, and $7.08 \mathrm{~mm}$ rut depths during 45 minutes. The achieved results indicated that, as the F-RCA content raised from 0 to $80 \%$ in HMA mixtures, the rut depth values increased up to $2.07,14.14,54.14$, and $144.14 \%$, respectively. However, the rut depth values of SMA mixtures reduced from $1.65 \mathrm{~mm}$ in VA-SMA to 1.6 and $1.41 \mathrm{~mm}$ in 20 and $40 \% \mathrm{~F}-$ RCA and then increased up to 2.97 and $3.28 \mathrm{~mm}$ in 60 and $80 \%$ F-RCA. Based on the test results, up to $40 \%$ F-RCA had a positive effect on the rutting of SMA mixtures. It was believed that the higher density and MS values (Figures 3 and 4) of SMA specimens containing 20 and 40\% F-RCA caused the better resistance in terms of rutting. 


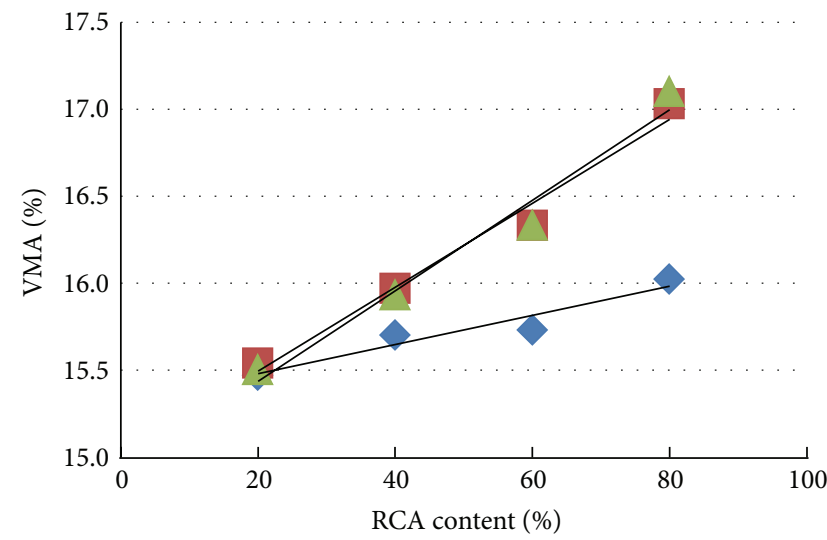

(a)

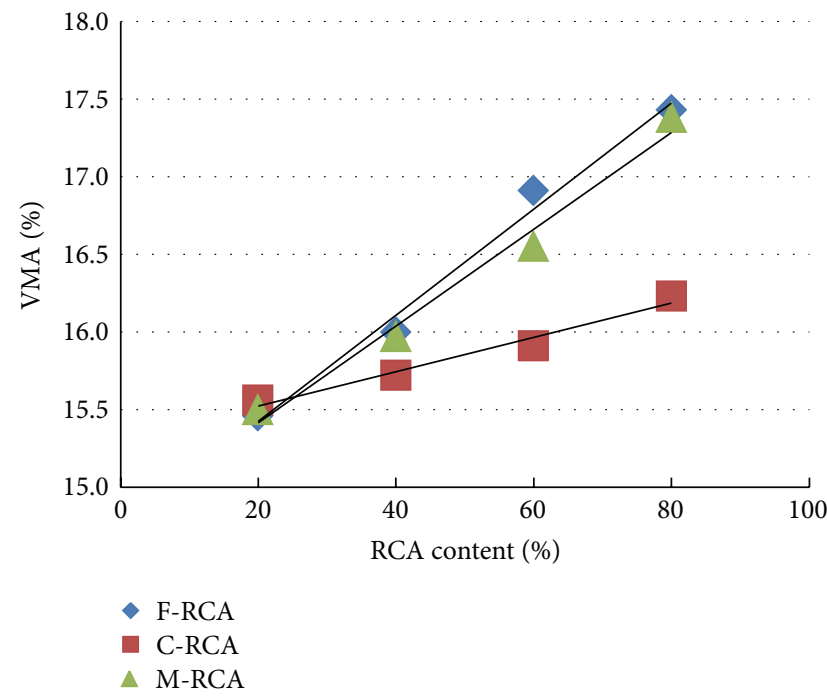

(c)

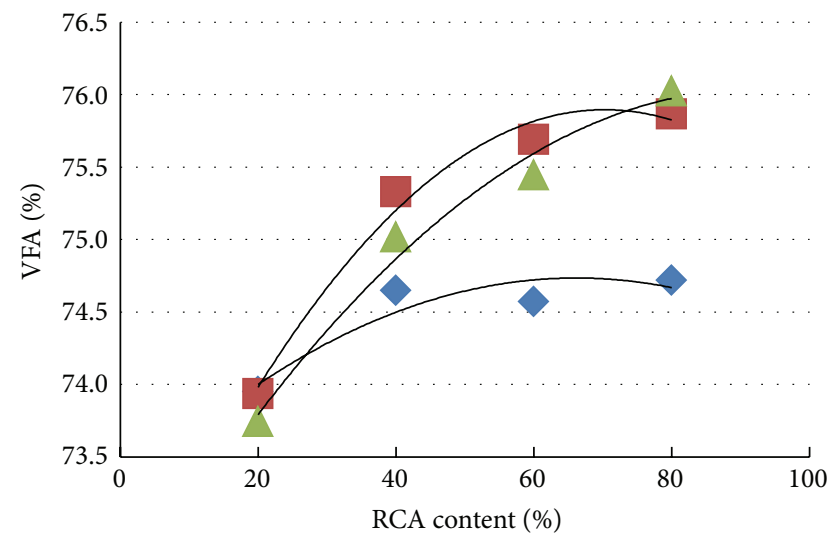

(b)

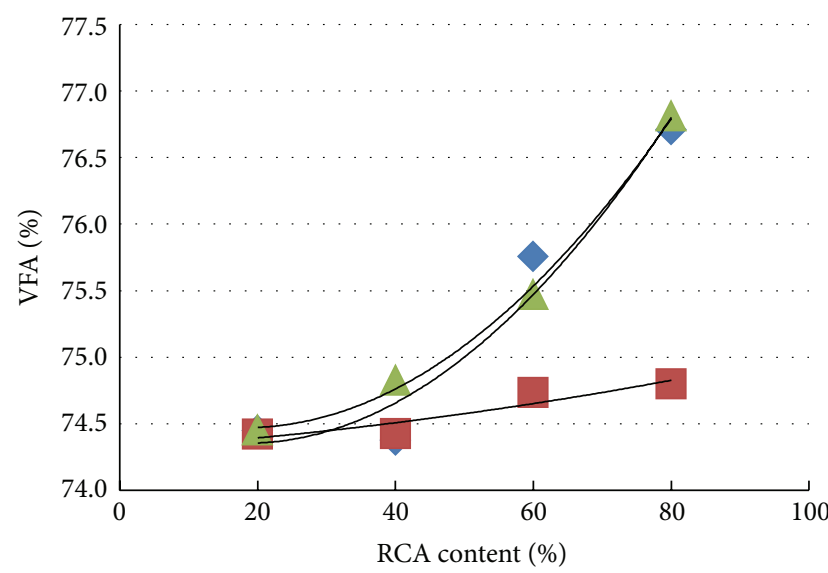

- F-RCA

- C-RCA

A M-RCA

(d)

Figure 5: (a) VMA of SMA specimens. (b) VFA of SMA specimens. (c) VMA of HMA specimens. (d) VFA of HMA specimens.
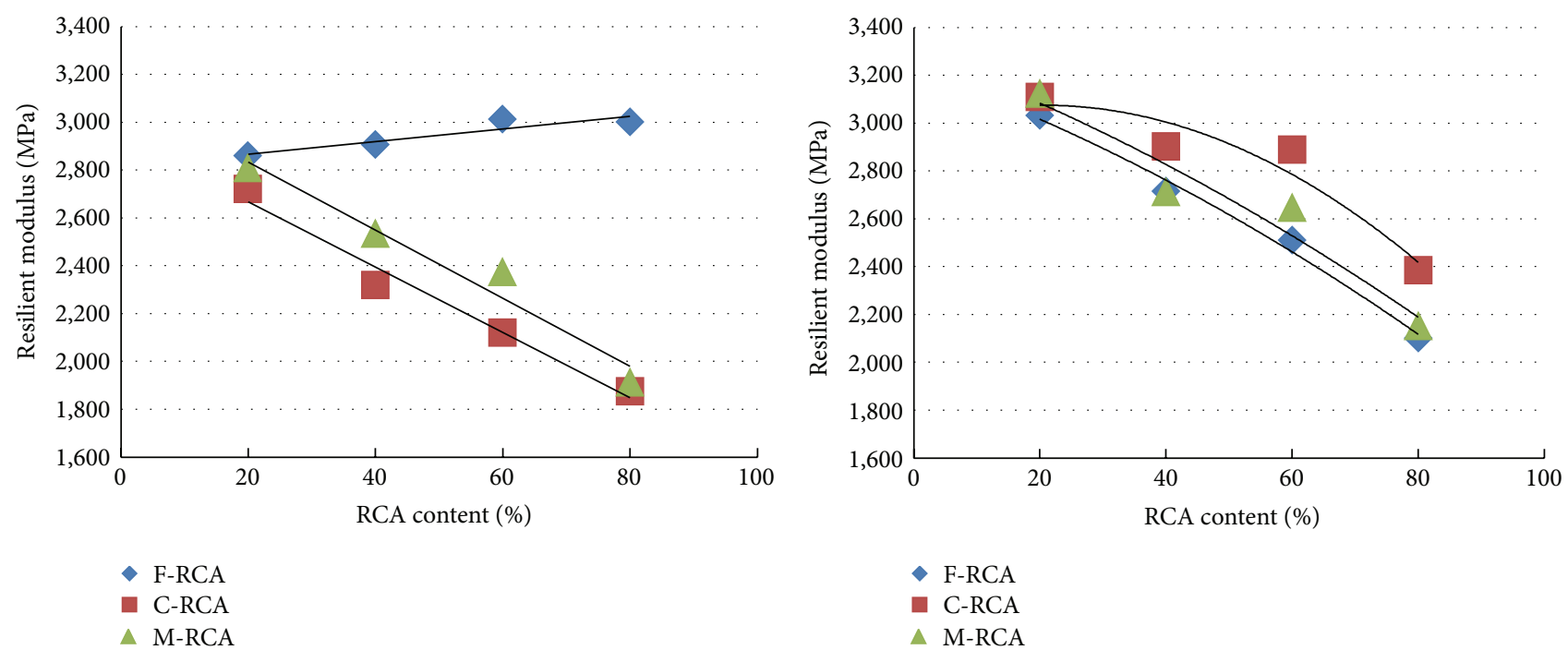

(a)

(b)

FIgURE 6: (a) Resilient modulus of SMA specimens. (b) Resilient modulus of HMA specimens. 


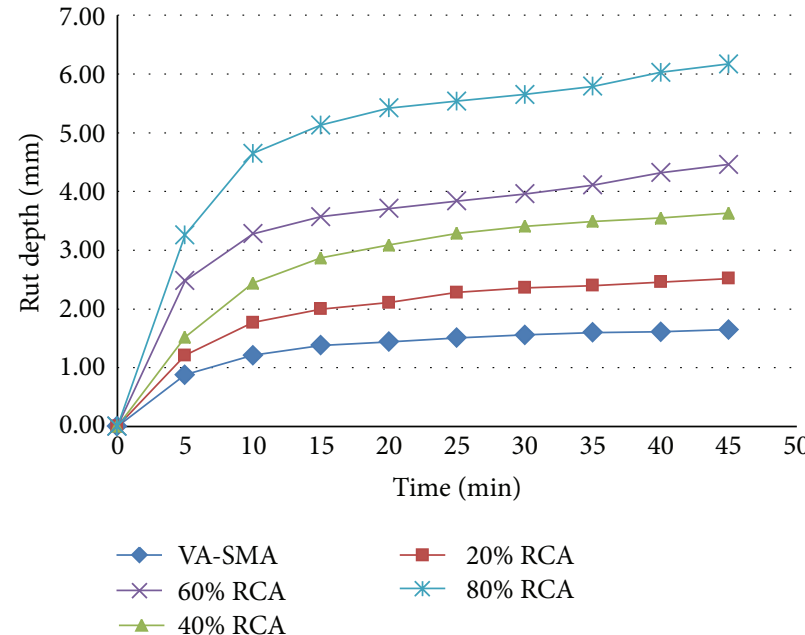

(a)

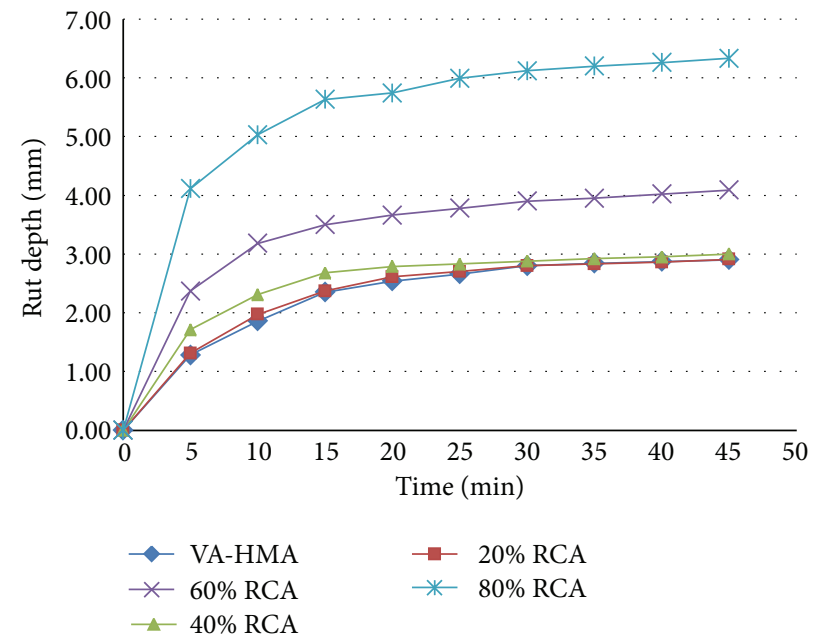

(b)

Figure 7: (a) Effect of C-RCA on rut depth of SMA specimens. (b) Effect of C-RCA on rut depth of HMA specimens.

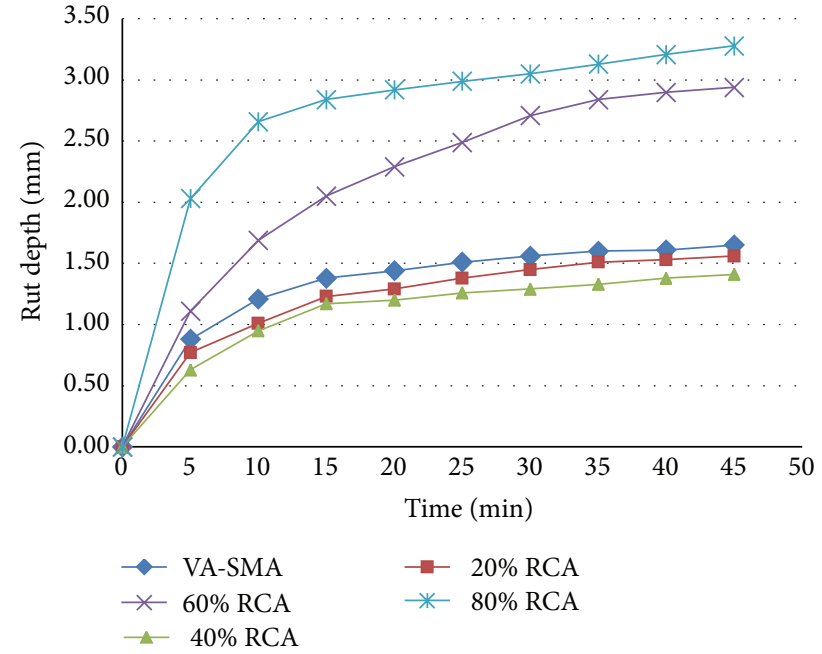

(a)

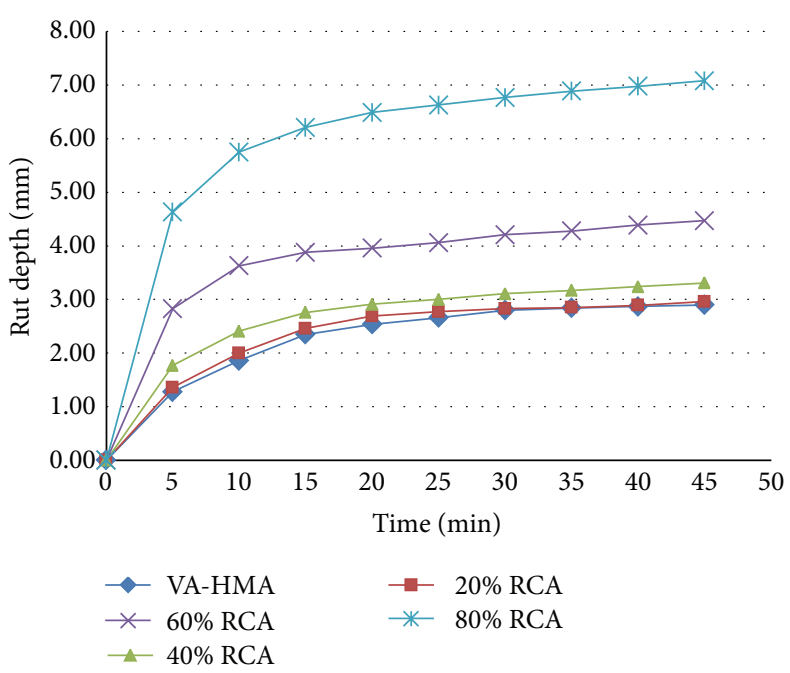

(b)

Figure 8: (a) Effect of F-RCA on rut depth of SMA specimens. (b) Effect of F-RCA on rut depth of HMA specimens.

The rut depth values of SMA and HMA specimens containing M-RCA are shown in Figure 9. The obtained test results indicated that the rut depth values of SMA and HMA specimens containing M-RCA were lower than the control mixes and any further increase in RCA content into the asphalt mixtures increased the values of rut depth. Based on the $\mathrm{BS}$ requirement the maximum allowable value of the rut rate at $45^{\circ} \mathrm{C}$ was $4 \mathrm{~mm}$ (Table 6). Even though the majority of the rut depth values was increased by utilizing RCA in both SMA and HMA mixtures, most of the specimens could fulfill the standard requirement in terms of rut depth except 60 and 80\% C-RCA and M-RCA in SMA mixtures and 80\% C-RCA and M-RCA and 60, 80\% F-RCA in HMA.

4.4. Wheel Tracking Rate. The wheel tracking rate $W_{\mathrm{TR}}$ is the second important factor which should be considered in rutting studies. The calculated wheel tracking rate $\left(W_{\mathrm{TR}}\right)$ for control mixtures ( $0 \%$ RCA) showed $0.34 \mathrm{~mm} / \mathrm{hr}$ for SMA and $0.40 \mathrm{~mm} / \mathrm{hr}$ for HMA. The rut rate values of SMA and HMA mixtures containing various amounts of RCA are displayed in Figure 10. Regardless of the amounts of utilized RCA content in the asphalt mixtures, the rut rate values of HMA were found considerably higher than SMA specimens. However, the calculated rut rate values of all the specimens were below $2 \mathrm{~mm} / \mathrm{hr}$ (BS requirement) except 60 and $80 \%$ CRCA in SMA specimens in which rut rate values increased up to 2.05 and $2.16 \mathrm{~mm} / \mathrm{hr}$. Generally, the mixtures containing higher amount of RCA showed higher values in terms of rut rate. However, there was no considerable change between VA-SMA compared to 20 and 40\% F-RCA and VA-HMA compared to 20 and $40 \%$ C-RCA but as the amount of RCA increases from 40 to 60 and $80 \%$ the rut rate growth became 


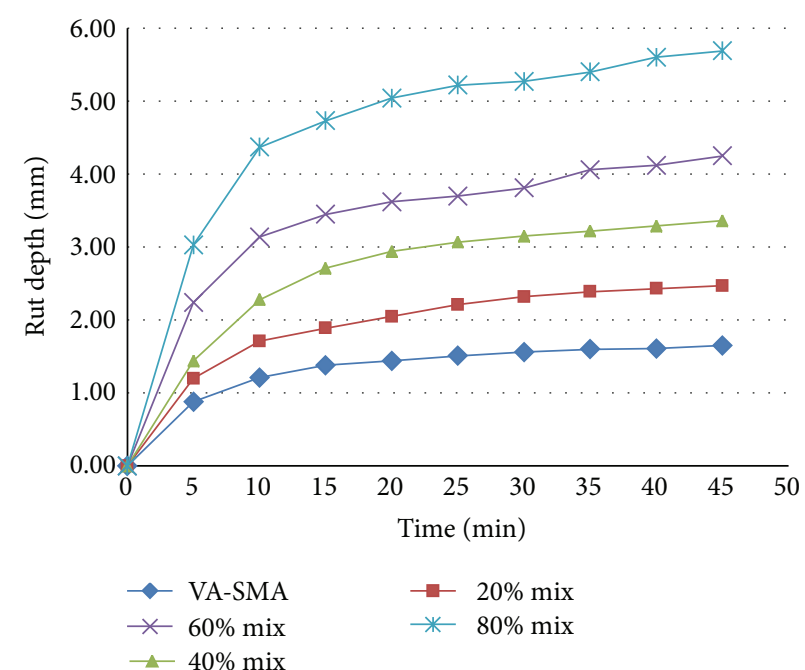

(a)

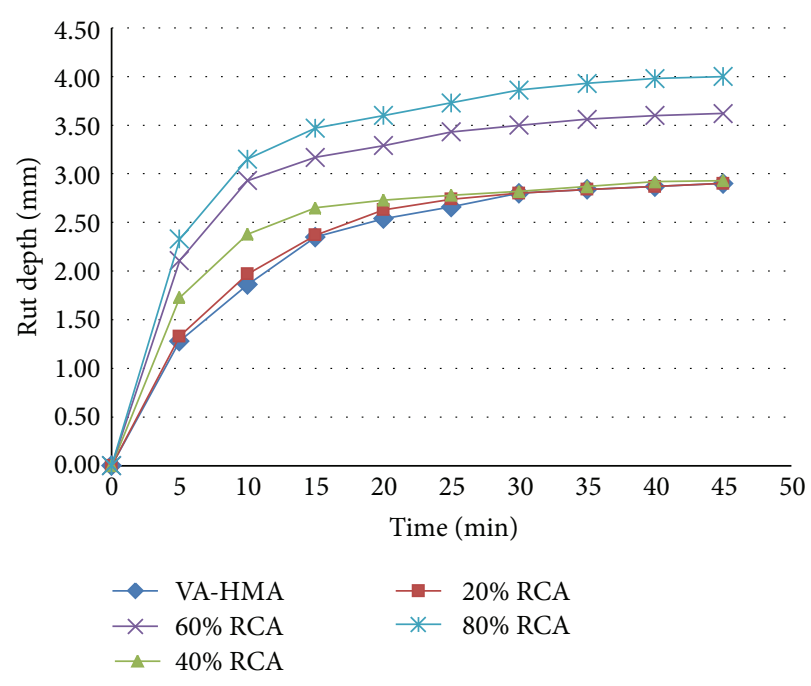

(b)

Figure 9: (a) Effect of M-RCA on rut depth of SMA specimens. (b) Effect of M-RCA on rut depth of HMA specimens.

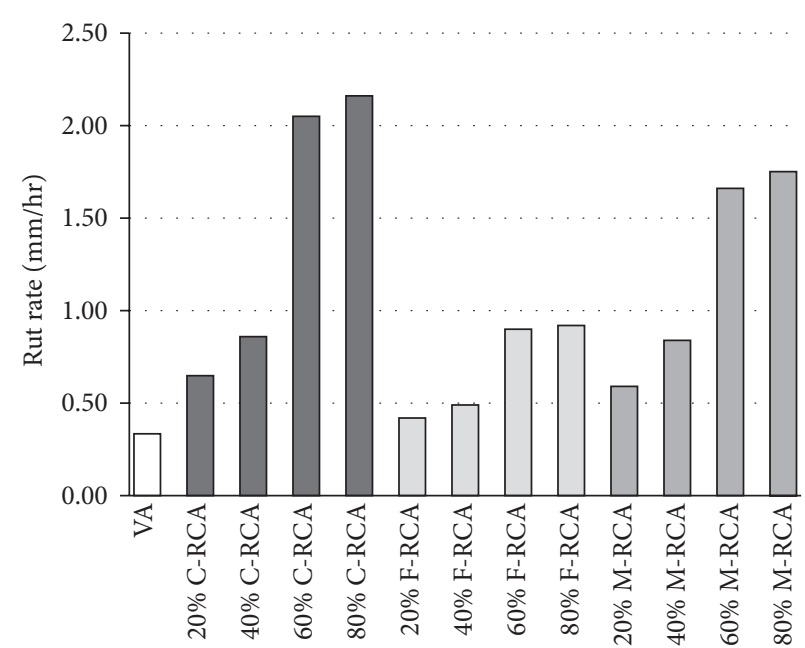

(a)

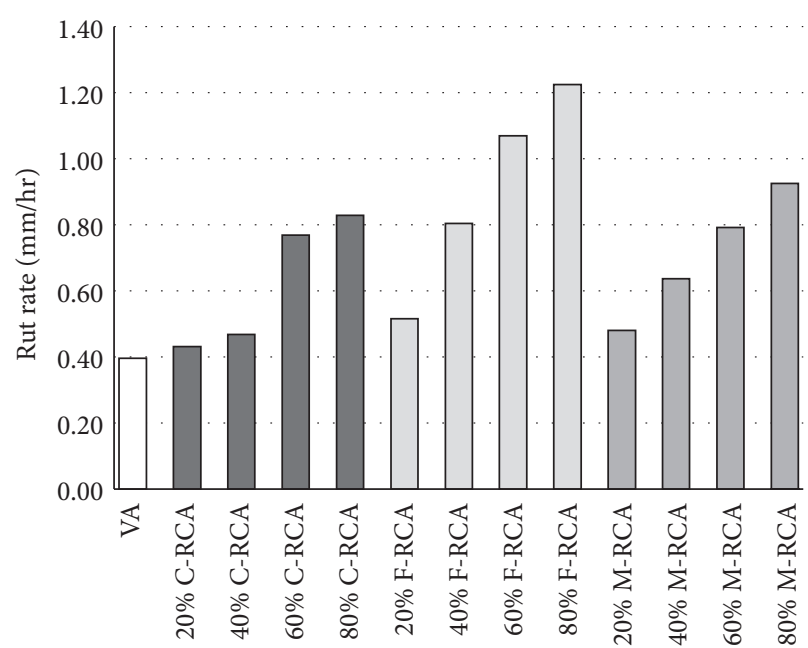

(b)

FIGURE 10: (a) Rut rate values of SMA mixtures including RCA content. (b) Rut rate values of HMA mixtures including RCA content.

more significant. This behavior can be attributed to the high amount of fines and low amount of coarse aggregates in HMA but the SMA aggregate gradation is vice versa.

\section{Analysis of Variance}

The objective of this research was to evaluate the volumetric and mechanical properties of stone mastic asphalt and hot mix asphalt mixtures containing recycled concrete aggregates. For this purpose, the performance of SMA and HMA mixtures containing various percentages of RCA has been evaluated based on experimental tests. However, to compare the differences among methods for research variables, the outcomes were statistically analyzed and the determination of the significance at certain confidence limits was performed with one-way analysis of variance (ANOVA). Prior to data analysis, all the data were subjected to normality test. The results revealed that all the variables were distributed normally and the homogeneity test result indicated that the variances were homogenous. The significance level $(\alpha)$ employed in this investigation was assumed to be 0.05 . Tables 7 and 8 present the variance analysis of SMA and HMA mixtures, respectively.

The results of ANOVA showed that all the measured $P$ values were smaller than the significance level $(\alpha)$ which indicated that the role and effect of various percentages of RCA in SMA and HMA mixtures were significantly different.

\section{Conclusions}

This paper has presented some of the experimental results obtained from the influence of recycled concrete aggregate 
TABLE 7: ANOVA outcomes for SMA test results.

\begin{tabular}{lcccc}
\hline Tests & SS & MS & $F$ & $P$ value \\
\hline OAC & 25.059 & 2.088 & 9.44 & $<0.01$ \\
Stability & 151.35 & 12.612 & 325.708 & $<0.01$ \\
Flow & 84.714 & 7.06 & 181.1 & $<0.01$ \\
Density & 0.051 & 0.004 & 6.163 & $<0.01$ \\
VTM & 0.094 & 0.008 & 228.397 & $<0.01$ \\
VMA & 11.539 & 0.962 & 32.35 & $<0.01$ \\
VFA & 23.068 & 1.922 & 217.121 & $<0.01$ \\
Resilient modulus & 5813509.59 & 484459.1 & 91561.39 & $<0.01$ \\
Rut depth & 161.43 & 13.452 & 8863.566 & $<0.01$ \\
Rut rate & 28.854 & 2.405 & $<0.01$ \\
\hline
\end{tabular}

TABLE 8: ANOVA outcomes for HMA test results.

\begin{tabular}{lcccc}
\hline Tests & SS & MS & $F$ & $P$ value \\
\hline OAC & 17.387 & 1.449 & 5.883 & 122.565 \\
Stability & 159.723 & 13.31 & 90.755 & $<0.01$ \\
Flow & 58.083 & 4.84 & 84.631 & $<0.01$ \\
Density & 0.073 & 0.006 & 6.972 & $<0.01$ \\
VTM & 0.088 & 0.007 & 89.263 & $<0.01$ \\
VMA & 17.833 & 1.486 & 36.321 & $<0.01$ \\
VFA & 32.013 & 2.668 & 144.752 & $<0.01$ \\
Resilient modulus & 4502850 & 375237.5 & 87945.32 & $<0.01$ \\
Rut depth & 134.489 & 11.207 & 1587.373 & $<0.01$ \\
Rut rate & 4.777 & 0.398 & & $<0.01$ \\
\hline
\end{tabular}

(RCA) on the performance of stone mastic asphalt (SMA) and hot mix asphalt (HMA) and the following conclusions are obtained.

(i) The attached excessive cements to the surface of the RCA could increase the bitumen absorption in the asphalt mixtures and reduce the adhesion between RCA and binder. During the experimental tests it was found that submerging and washing RCA before being utilized in the asphalt mixture could considerably increase the performance of the HMA and SMA mixtures.

(ii) RCA has a porous structure, with lower specific gravity and higher absorption in comparison with virgin aggregates. While the amounts of coarse aggregates are considerably higher in SMA mixtures, any replacement of VA coarse aggregates with C-RCA can highly affect the mixture performance due to lower density and C-RCA fracture under pressure. Moreover, in HMA, due to higher amount of fines compared to coarse aggregates, any replacement of VA fines with F-RCA causes a higher demand of asphalt contents and reduces the density values of the mixtures, which affect the HMA performance.

(iii) The technical basis of SMA is a stone skeleton with stone-on-stone contact which resists the shear forces created by applied loads and results in higher resistance to rutting. Regardless of the RCA sizes, the growth trend of rut depth and rut rate values in the asphalt mixtures containing 20 and $40 \%$ RCA is considerably lower than 60 and $80 \%$ and as the level of RCA increased up to 60 and $80 \%$, the level of rut resistance reduction became more significant.

(iv) Even though utilizing RCA in asphalt mixtures could affect the volumetric and mechanical properties of the mixtures, but based on the demands of the project and traffic volume, using specific amounts of RCA in SMA and HMA mixtures can easily satisfy the standard requirements. These findings can promote the reuse and recycling of waste materials, especially RCA, in pavement industries to generate economic and environmental benefits in the future.

\section{Conflict of Interests}

The authors declare that there is no conflict of interests regarding the publication of this paper.

\section{Acknowledgments}

The authors would like to acknowledge the Center of Research Grant Management, Institute of Research Management and Monitoring of University of Malaya (UM), for the financial support of this project (Project no. ER030/2011A). 


\section{References}

[1] Y. Xue, H. Hou, S. Zhu, and J. Zha, "Utilization of municipal solid waste incineration ash in stone mastic asphalt mixture: pavement performance and environmental impact," Construction and Building Materials, vol. 23, no. 2, pp. 989-996, 2009.

[2] L. P. T. L. Fontes, G. Trichês, J. C. Pais, and P. A. A. Pereira, "Evaluating permanent deformation in asphalt rubber mixtures," Construction and Building Materials, vol. 24, no. 7, pp. 11931200, 2010.

[3] M. C. Arm, "Self-cementing properties of crushed demolished concrete in unbound layers: results from triaxial tests and field tests," Journal of Waste Management, vol. 21, no. 3, pp. 235-239, 2001.

[4] W. L. Huang, D. H. Lin, N. B. Chang, and K. S. Lin, "Recycling of construction and demolition waste via a mechanical sorting process," Resources, Conservation and Recycling, vol. 37, no. 1, pp. 23-37, 2002.

[5] C. McGrath, "Waste minimisation in practice," Journal of Resources Conservation and Recycling, vol. 32, no. 3-4, pp. 227238, 2001.

[6] U.-M. Mroueh and M. Wahlström, "By-products and recycled materials in earth construction in Finland-an assessment of applicability," Resources, Conservation and Recycling, vol. 35, no. 1-2, pp. 117-129, 2002.

[7] K. A. Pihl and O. Milvang-Jensen, "The motivation factors in the development and sustainment of a well-functioning recycling industry for road and non-road byproducts in Denmark," in Proceedings of the Specialty Conference on Beneficial Use of Recycled Materials in Transportation Applications, pp. 19-27, University of New Hampshire, Arlington, Va, USA, November 2001.

[8] C. S. Poon, Z. H. Shui, L. Lam, H. Fok, and S. C. Kou, "Influence of moisture states of natural and recycled aggregates on the slump and compressive strength of concrete," Cement and Concrete Research, vol. 34, no. 1, pp. 31-36, 2004.

[9] Aggregates advisory service-UK, "Construction and demolition waste management practices and their economic impacts," Study for DGXI- European commission Digest 16, 1999.

[10] CSIR, "Reusing construction and demolition waste," Building and Construction Technology, Techno Brief, 2000.

[11] Y. D. Wong, D. D. Sun, and D. Lai, "Value-added utilisation of recycled concrete in hot-mix asphalt," Journal of Waste Management, vol. 27, no. 2, pp. 294-301, 2007.

[12] FHWA, Summary of California recycled concrete aggregate review. U.S. department of transportation. Federal Highway Administration, 2003, http://www.fhwa.dot.gov/pavement/ recycling/rcaca.cfm.

[13] Focus, "Recycled concrete study identifies current uses best practices," U.S. department of transportation, Federal Highway Administration, Publication no. FHWA-HRT-04-024, 2004, http://www.tfhrc.gov/FOCUS/apr04/01.htm.

[14] A. M. Schutzbach, "Case study of a full-depth asphalt concrete inlay," Transportation Research Record 1337, Flexible Pavement Construction, Performance and Recycling, Transportation Research Board, National Research Council, Washington, DC, USA, 1992.

[15] S. Paranavithana and A. Mohajerani, "Effects of recycled concrete aggregates on properties of asphalt concrete," Resources, Conservation and Recycling, vol. 48, no. 1, pp. 1-12, 2006.

[16] A. Topal, A. U. Ozturk, and B. Baradan, "Use of recycled concrete aggregates in hot-mix asphalt," in Proceeding of 8th
CANMET/ACI International Conference on Recent Advances in Concrete Technology, vol. SP- 235-20, pp. 282-295, American Concrete Institute, Quebec, Canada, June 2006.

[17] J. Mills-Beale and Z. You, "The mechanical properties of asphalt mixtures with recycled concrete aggregates," Construction and Building Materials, vol. 24, no. 3, pp. 230-235, 2010.

[18] E. Ahmadinia, M. Zargar, M. R. Karim, and M. Abdelaziz, "Performance evaluation of utilization of waste polyethylene terephthalate (PET) in stone mastic asphalt," Journal of Construction and Building Materials, vol. 36, pp. 984-989, 2012.

[19] S. Tayfur, H. Ozen, and A. Aksoy, "Investigation of rutting performance of asphalt mixtures containing polymer modifiers," Journal of Construction and Building Materials, vol. 21, no. 2, pp. 328-337, 2007.

[20] X. Lu and P. Redelius, "Effect of bitumen wax on asphalt mixture performance," Construction and Building Materials, vol. 21, no. 11, pp. 1961-1970, 2007. 

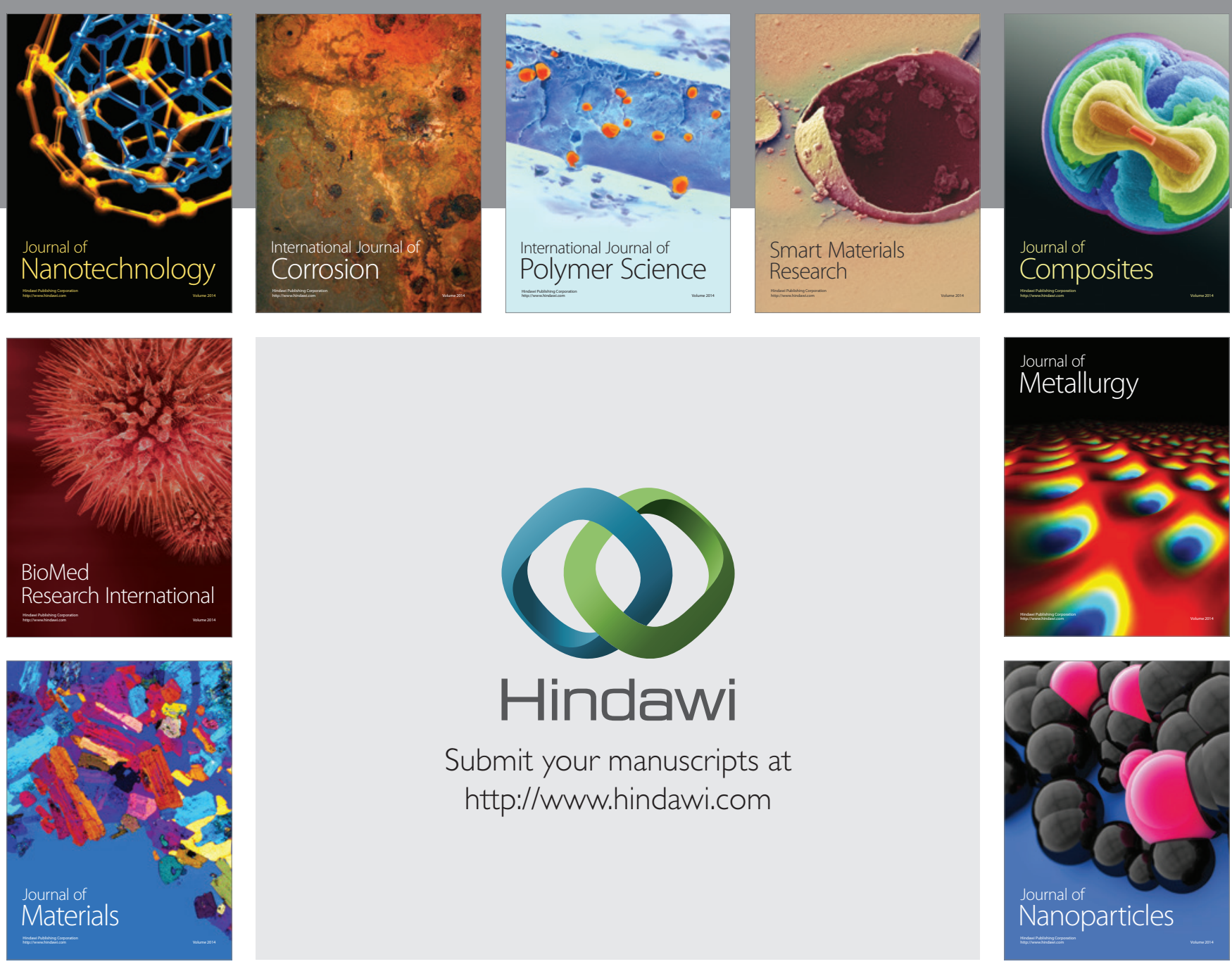

Submit your manuscripts at http://www.hindawi.com
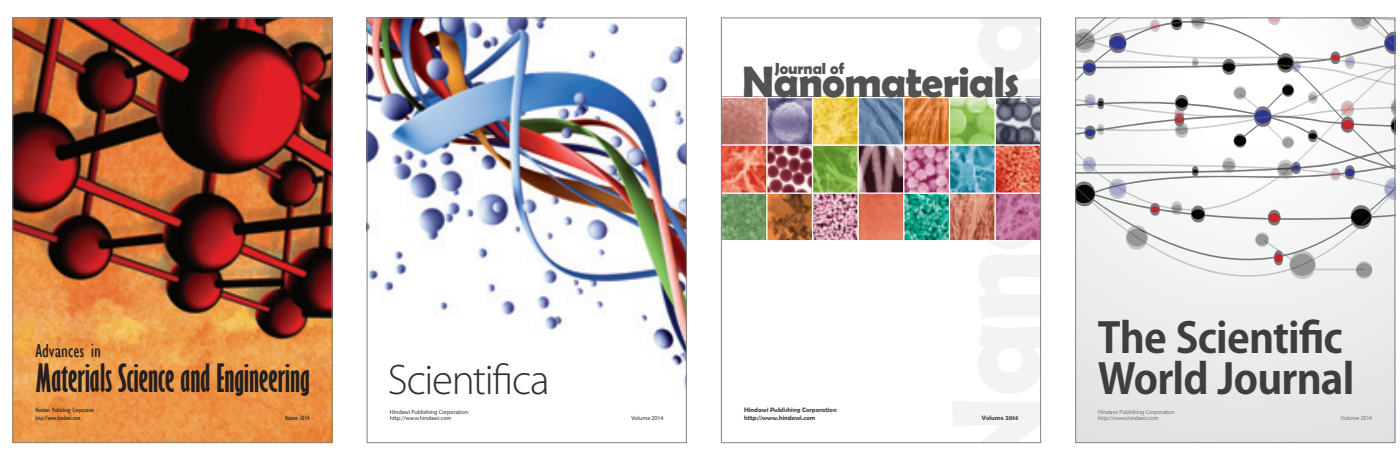

\section{The Scientific World Journal}
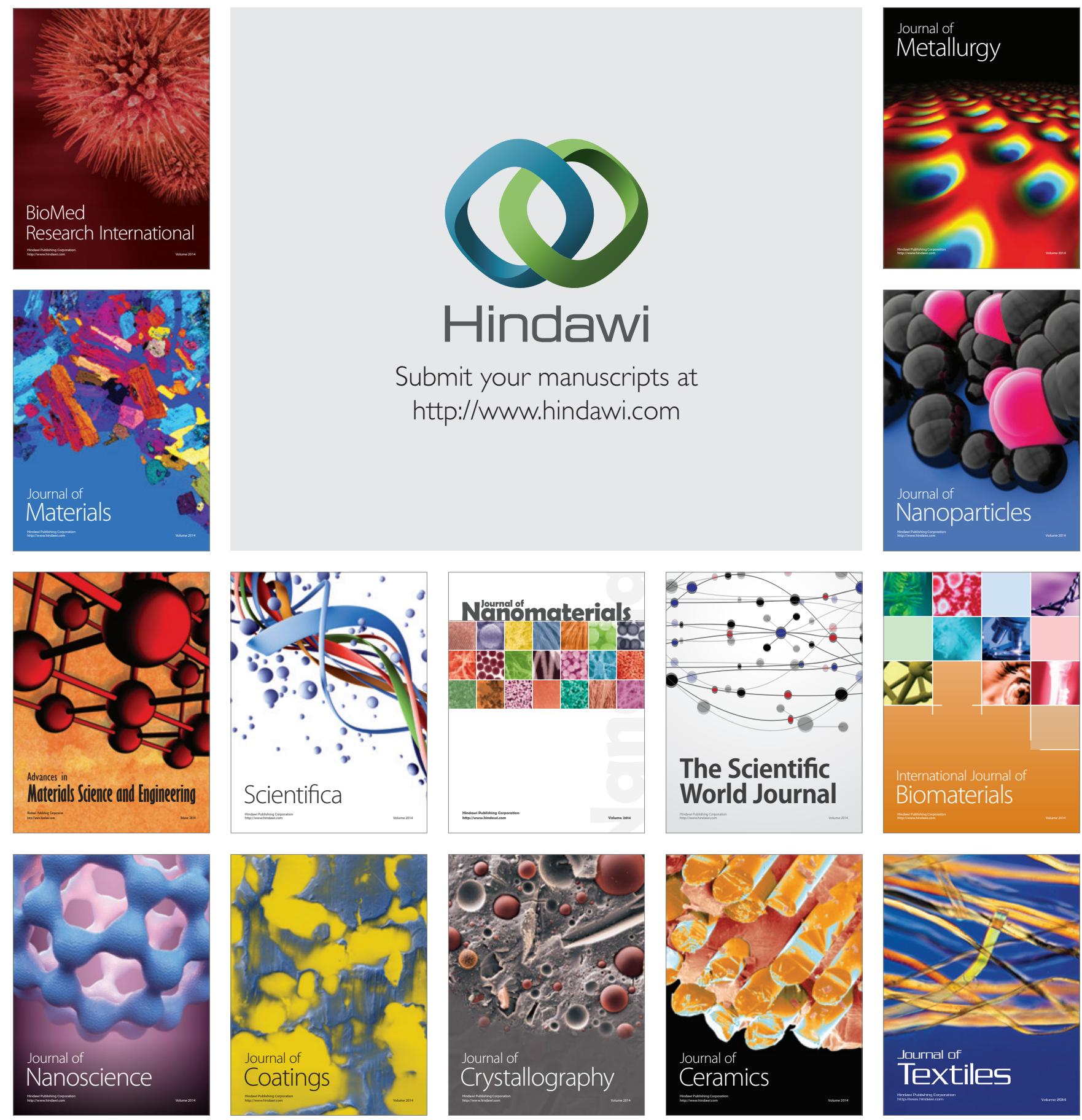